\title{
New Confirmed Deaths Rising Much Less than New Confirmed Cases in the Second Wave of Severe Acute Respiratory Syndrome Coronavirus 2 Infection in Western Europe
}

Since October 2020, Western Europe has been characterized by a second wave of Coronavirus Disease 2019 (COVID-19) infection. Figure 1A presents the daily new cases of Severe Acute Respiratory Syndrome Coronavirus 2 (SARS-CoV-2) in Western Europe [1,2]. The number of new cases has been sharply increasing in many countries such as the United Kingdom, The Netherlands, and Belgium.
The latest positive rate (Figure 1B) is still lower compared with the very high values experienced during the first outbreak when mostly sick peoples were tested, but is in general relatively high, especially for Belgium, where the fatality rates were higher during the first wave of infection, and the curve seems now declining. Despite this apparent significant number of novel infections, the
A

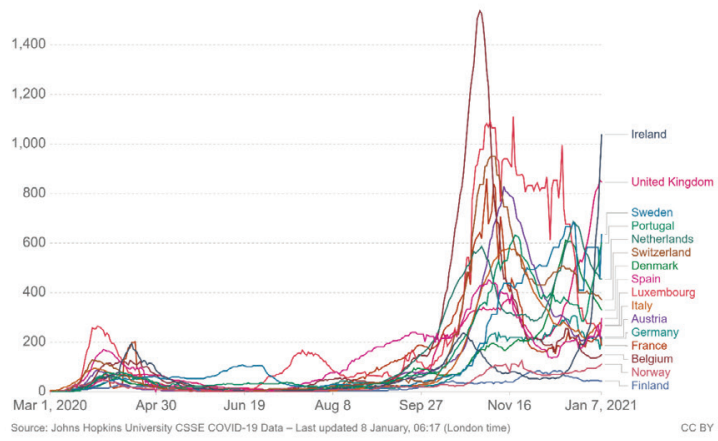

C

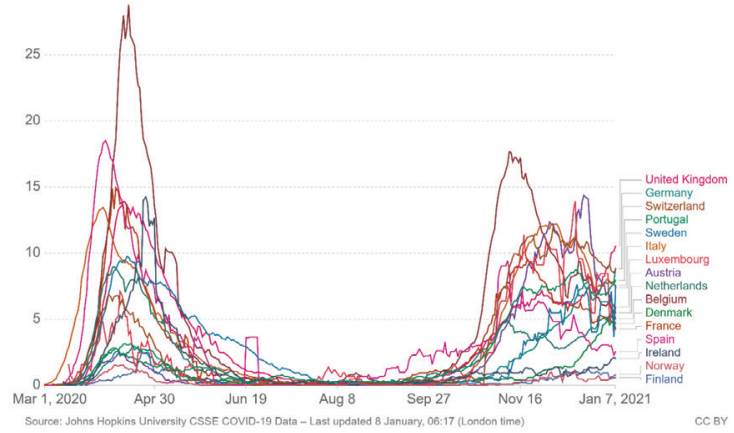

B

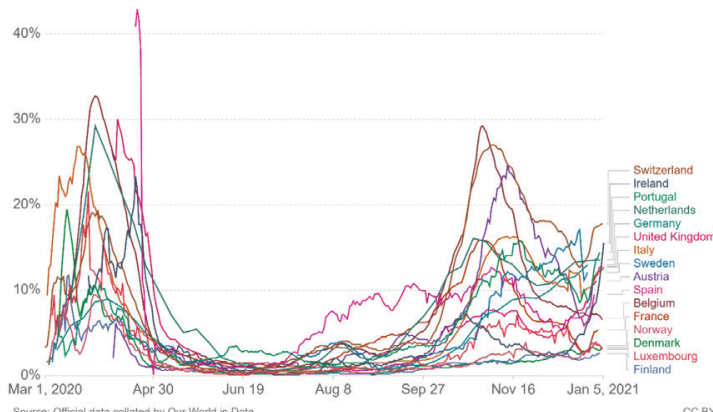

$\mathrm{D}$

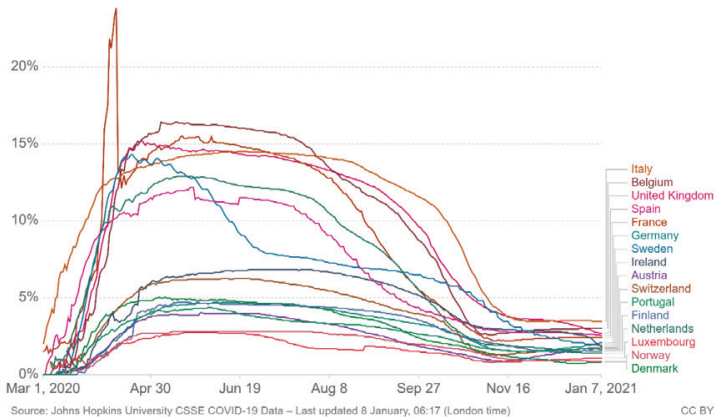

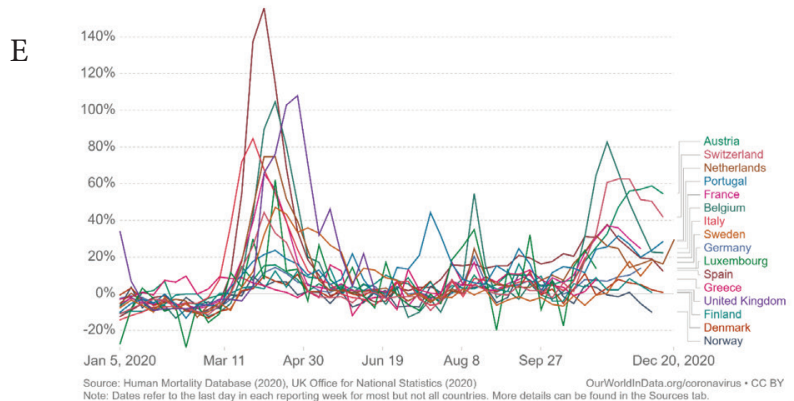

Figure 1 Seven-day rolling averages of severe acute respiratory syndrome coronavirus 2 (SARS-CoV-2) new cases (A), positive rate in the tests (B), new deaths (C), and case fatality rate (D) plus excess mortality (E) in countries of Western Europe. Images from ourworldindata.org. CC BY. 
daily new deaths per million people are increasing at a slower pace (Figure 1C). The case fatality rate (Figure 1D) has been decreasing since the end of March 2020 and beginning of April 2020, when the first wave of infection peaked. The excess mortality (Figure 1E) that suffers from lack of data updates in some countries is lower in countries that experienced a more severe first wave.

Many explanations have been proposed for the observed reduction of fatalities versus confirmed cases. More testing, the changing age profile of infected patients, and improved care are the most likely reasons why mortality rates are lower in the second wave. The lag time between infection and death has also some relevance, even if the number of deaths has not increased significantly many weeks after the number of cases began to increase. Testing is certainly more broadly available, detecting additional mild or asymptomatic individuals. Not all those detected as "positive" by the current polymerase chain reaction SARS-CoV-2 test are infectious. This qualitative test, which provides a "yes-no" answer without specifying the viral load, identifies the Cycle Threshold (CT) as "positive" also in patients with only a minimal amount of viral fragments. Although a CT of 40 is presently used, the US Centers of Disease Control and Prevention admits that a CT of 33 would be more appropriate. Others suggest lowering the CT further down to 30 (or even lower). During the first outbreak, only the very sick were tested, and a positive result was achieved on average with a CT of less than 20. Thus, certainly, the number of positive cases is currently overrated.

In the first wave of infection, the elderly in care homes have been the main driver of the fatality rate. There is now a greater share of younger people testing positive, and conversely a decreasing share of older people. Overwhelmed health systems and many older individuals (or people with comorbidities) infected are not that common anymore, and this may contribute to explain the reduced number of fatalities during the second wave. Those at greatest risk are now minimizing contacts, whereas those at least risk are resuming social contacts. Another likely explanation is the reduced viral load for those infected at home, rather than those who became infected in care homes and hospitals during the first outbreak. The viral load may indeed correlate with mortality [3], and viral loads in nursing homes and hospitals were by far larger than those in private houses. Improved treatments may also contribute to a better outcome of the infection. Finally, another factor considered is the opportunity of genetic mutations of SARS-CoV-2 toward increased infectivity but reduced fatality. There is, however, a lack of evidence behind this hypothesis. Viruses constantly evolve [4]. In the case of the Spanish flu, there have been four waves of infection, with the second the deadliest [5]. More information is certainly needed to understand if SARS-CoV-2 is currently evolving toward a more infectious but less lethal virus. The proposed data also permit the discussion of the efficacy and sustainability of SARS-CoV-2 restrictions. Countries with fewer restrictions such as Sweden did not perform worse than countries with more restrictions such as Belgium and the United Kingdom, and will likely perform better during this second wave of infection where different approaches are similarly emerging.

\section{CONFLICTS OF INTEREST}

The author declares no conflicts of interest.

\section{REFERENCES}

[1] Boretti A. After less than 2 months, the simulations that drove the world to strict lockdown appear to be wrong, the same of the policies they generated. Health Serv Res Manag Epidemiol 2020;7;1-11.

[2] Boretti A. Sustainable post Covid19 lockdown strategy through evidence-based policy: analysis of Covid19 fatalities across Europe. Integr J Med Sci 2020;7;172. Available from: https:// www.mbmj.org/index.php/ijms/article/view/172.

[3] Pujadas E, Chaudhry F, McBride R, Richter F, Zhao S, Wajnberg A, et al. SARS-CoV-2 viral load predicts COVID-19 mortality. Lancet Respir Med 2020;8;e70.

[4] Webster RG, Bean WJ, Gorman OT, Chambers TM, Kawaoka Y. Evolution and ecology of influenza A viruses. Microbiol Rev $1992 ; 56 ; 152-79$.

[5] Reid AH, Fanning TG, Hultin JV, Taubenberger JK. Origin and evolution of the 1918 "Spanish" influenza virus hemagglutinin gene. Proc Natl Acad Sci U S A 1999;96;1651-6.

\author{
Alberto Boretti*, (i) \\ Deanship of Research, Prince Mohammad Bin Fahd University, Al Khobar, \\ Saudi Arabia \\ Email:a.a.boretti@gmail.com \\ Peer review under responsibility of the Dr. Sulaiman Al Habib Medical Group
}

